\title{
Retraction Note to: Pre-dispersal seed predation in gynodioecious Geranium sylvaticum is not affected by plant gender or flowering phenology
}

\section{Sandra Varga ${ }^{1}$}

Published online: 7 April 2020

(c) Springer Nature B.V. 2020

\section{Retraction to:}

Arthropod-Plant Interactions (2014) 8:253- 260 https://doi.org/10.1007/s11829-014-9306-3

The Editor-in-Chief has retracted this article [1]. According to the University of Jyväskylä, the author did not have permission to use the data for the research purposes described in this article. The University of Jyväskylä has stated that the data collected from the Konnevesi long-term field experiment forms a database protected under the Finnish Copyright Act, Section 49. The producer, in this case the University of Jyväskylä, holds the exclusive rights over the database. The author agrees to this retraction.

\section{Reference}

1. Varga S (2014) Pre-dispersal seed predation in gynodioecious Geranium sylvaticum is not affected by plant gender or flowering phenology. Arthropod-Plant Interact 8:253-260. https://doi. org/10.1007/s11829-014-9306-3

Publisher's Note Springer Nature remains neutral with regard to jurisdictional claims in published maps and institutional affiliations.

The original article can be found online at https://doi.org/10.1007/ s11829-014-9306-3.

Sandra Varga

sandra.varga@jyu.fi; sandravarga30@hotmail.com

1 Department of Biological and Environmental Science, University of Jyväskylä, P.O. Box 35, 40014 Jyväskylä, Finland 